\title{
Characteristics of self-managing teams in rapid product development projects
}

\section{Harri Kaikkonen* and Harri Haapasalo}

Department of Industrial Engineering and Management, University of Oulu,

PL 4610, 90014 Oulun Yliopisto, Finland

Email: harri.kaikkonen@oulu.fi

Email: harri.haapasalo@oulu.fi

*Corresponding author

\author{
Kai Hänninen \\ Kerttu Saalasti Institute, \\ University of Oulu, \\ Pajatie 5, 85500 Nivala, Finland \\ Email: kai.hanninen@oulu.fi
}

\begin{abstract}
Product development organisations are facing an increasing amount of rapid, small-scale development projects to fulfil market and customer needs. Self-managing teams have been proposed as effective means in creating new radical innovation, but their use has not been widely studied in smaller and faster product development projects, which are increasing in numbers. A multiple-case study was conducted to analyse seven business-to-business companies' product development models and the use of self-management in their rapid product development teams. The findings indicate that the companies use very similar characteristics of self-management to support rapid product development projects, but all characteristics of self-management do not support rapid product development teams. Notable success factors for rapid product development were dedicating competent developers for rapid projects, co-locating the development team, effective face-to-face communication and implementing a defined, but flexible workflow for rapid product development.
\end{abstract}

Keywords: product development; new product development; NPD; product development process; self-management; self-managing teams; rapid product development; B2B; self-organisation; agile methods; product development teams; rapid development.

Reference to this paper should be made as follows: Kaikkonen, H., Haapasalo, H. and Hänninen, K. ( $\mathrm{xxxx)}$ 'Characteristics of self-managing teams in rapid product development projects', Int. J. Value Chain Management, Vol. X, No. Y, pp.xxx-xxx.

Biographical notes: Harri Kaikkonen is a Doctoral student at Industrial Engineering and Management in the University of Oulu. He holds a Master's in Industrial Engineering and Management (Technology Management) and is writing a dissertation on the application of agile development methods in product development, while working in the Product Management research unit at the University of Oulu. His other research interests include lean thinking, 
software development processes, change management, and organisational management. His list of scientific publications includes several journal and conference papers on these topics.

Harri Haapasalo is a Professor of Product Management at Industrial Engineering and Management, University of Oulu in Finland. He has two main areas of research; one in product management, product development and second one in the area of complex systems management, lean construction and business models. He has been very active in obtaining research projects, and active in journal publications. His list of publications contains more than 200 international items. He has supervised more than 20 doctoral theses and been external examiner for more than 20 doctoral dissertations.

Kai Hänninen is a Post-doctoral Research Fellow at the University of Oulu, Finland. He holds a Doctorate in Industrial Engineering and Management, a Master's degree in Engineering (Embedded Systems) and Bachelor's in Civil Engineering and Computer Engineering. Before entering academic research, he worked more than 25 years at various managerial levels in R\&D and technology management in the telecommunications and construction industry. His research interest is two folded with companies' growth and business management, with a particular focus on service and technology based companies. In more detail about how companies are able to manage growth and maintain a full functionality of $R \& D$ operations. In $R \& D$ operations, the main focus is on rapid product or service development. In the area of business growth, a focus area is how to boost companies generate a new value proposition from an idea/invention to a commercial solution. He has authored over 20 international scientific articles.

\section{Introduction}

Product development is a key component in the success of companies all over the world (Clark and Fujimoto, 1991; Wheelwright and Clark, 1992). The speed at which new products are brought to the market has been reducing constantly, and delays in bringing new products to the market leads to reduced sales and profits (Hilletofth et al., 2010). Companies are therefore looking at different methods with which to bring new products to market in an ever faster pace (Barczak et al., 2009; Langerak and Hultink, 2008; Millson et al., 1992; Zhou and Zhao, 2010). Reductions of lead-time can be sought for example from processes (Cooper, 2014), methods (Karlstrom and Runeson, 2005), and tools (Smith and Reinertsen, 1997).

One way to help organisations arrange their development resources more effectively is thinking of alternative ways of working for different types of development projects (Barczak et al., 2009; Cooper, 2014). Although there have been considerable interests in the scientific community for finding improvements to the process of developing new products, less attention has been given to small, rapid product development projects, even though their share has been increasing and now account for over $60 \%$ of all development projects (Cooper et al., 2004).

While the amount of incremental product development has been rising, there has been increasing interest in utilising agile development methods of the software community also in product development (Cooper, 2016; Rigby et al., 2016; Sommer et al., 2015). The utilisation of self-management in development teams is centric to agile development 
(Hoda et al., 2010; Moe et al., 2008), and is potentially beneficial also for product development. It is worthwhile to analyse how self-managing teams are utilised in smaller product development projects and if there are any obstacles in the utilisation of self-management in them. The use of self-managing teams is not always easy, and conflicts may cause the teams to become ineffective (Langfred, 2007). It is of value to understand how the characteristics of self-management are utilised in product development to get all possible benefits out of self-managing teams and avoid the involved pitfalls.

This paper focuses on the use of self-management in product development teams in rapid product development projects. More specifically, the purpose of the paper is to analyse how the different characteristics of self-managing teams are utilised during smaller product development projects which require fast delivery. The study was conducted as an interview study in seven companies. The research questions of this study are defined as:

RQ1 How do companies utilise the characteristics of self-managing teams in rapid product development projects?

RQ2 What are the perceived success factors for rapid product development by the analysed companies and how are they related to the characteristics of self-managing teams.

This paper begins with an outline of different product development models and a definition of rapid product development. Next, the characteristics of self-managing teams and literature on the use of self-managing teams in product development are presented shortly. The third section presents the research method and process which was used in this study, including basic information on the analysed companies. The fourth section describes the use of rapid product development in the companies, together with a combined analysis of the use of self-management in rapid product development. The results are further discussed in a separate discussion section detailing the implications of the findings.

\section{Literature review}

\subsection{Classification of product development processes}

Companies' product development processes can be organised in multiple ways. Perhaps the most well-known description of a product development process is the stage-gate development process by Cooper (1993). However, a single product development process is not usually suitable for all types of projects, forcing companies to utilise several processes for different types of projects, or to modify their general process case-by-case (Cooper, 2014; Kaikkonen et al., 2016).

One common way to differentiate different types of development projects within an organisation is by their size and scope (Barczak et al., 2009; Cooper, 2014; Kaikkonen et al., 2016). Cooper (2014) has stated that companies may approach different sized product development projects with three processes and has split the traditional stage-gate product development process into three versions based on the size and complexity of the development projects, including: Full, Lite and Xpress stage-gate processes (Cooper, 
2014). In innovation literature, differentiating product development projects between the size and nature of development changes have been referred as radical and incremental innovation, where radical innovation means fundamental changes that represent revolutionary changes in technology and incremental innovation refers to minor improvements or simple adjustments in current technology (Devar and Dutton, 1986). However, there is a lot of ambiguity and overlap within the definitions in innovation literature which complicates the use of innovation terminology while discussing the separation of product development processes (Garcia and Calantone, 2002).

The stage-gate product development process is meant to create new products into the marketplace. However, there are also other types of product development processes, which are not only intended for creating new sales items, but to improve or modify existing sales items in a company's product portfolio (Jarratt et al., 2011; Wright, 1997). The product development process of improving existing products is often referred to as engineering change management (ECM). Jarratt et al. (2011) define engineering changes as "changes to parts, drawings or software that have already been released during the product design process, regardless of the scale of the change”. ECM processes are widely used in companies to separate incremental product development projects from the development projects that create new sales items. The ECM process complements the separation of new product development processes of Cooper (2014), by taking into account development projects that are not intended to result in new sales items.

With the inclusion of ECM as a product development process four different types of product development models were separated by modifying the processes by Cooper (2014) and Jarratt et al. (2011) (Figure 1). In order to clarify the nature of Cooper's three development processes, they have been renamed in this study as large and complex new product development, medium-sized product development and rapid product development (Figure 1). The term rapid product development is used here to describe the scope and nature of the development projects, and is not to be confused with rapid product development (RPD), a term sometimes utilised when discussing advances in rapid prototyping and computer-aided iterative development (e.g., Bernard and Fischer, 2002; Bullinger et al., 2000).

This separation of product development models was used during the research process to help the interviewees consider their internal product development processes.

Gautam and Singh (2008) have suggested that there are three reasons for incorporating incremental changes to a product's design; bringing innovation, continuous improvement and forced changes. Incremental changes make products more attractive to the customer and bring increased sales and revenue for business-to-business (B2B) companies (Gautam and Singh, 2008). Although ECM can be used to create new sales items as well (Jarratt et al., 2011), it is generally not used to create new sellable products to a company's product portfolio. ECM has been separated from the other three product development models as a process that does not result in new sales items. Instead, ECM projects are improvements to existing items in forms of cost reduction versions or quality improvements. 
Figure 1 Four categories of product development

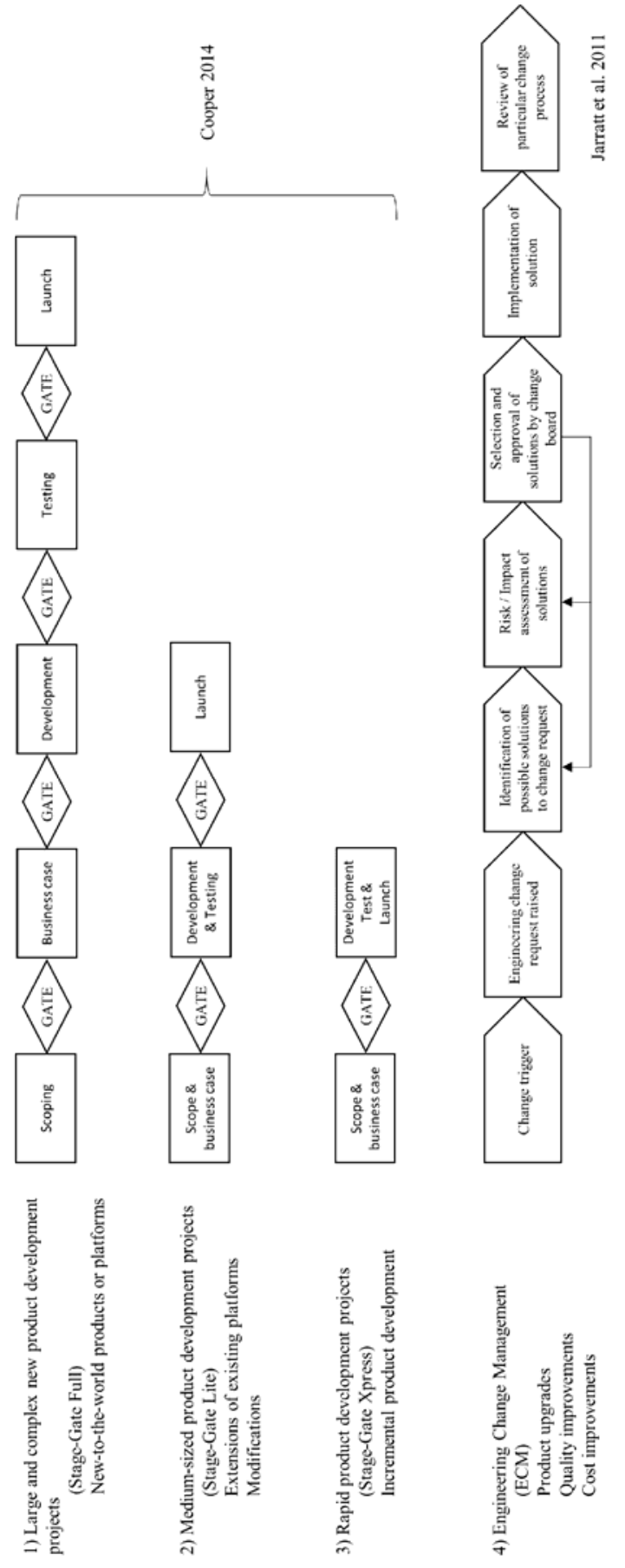


This study focuses on rapid product development, the third category of product development in Figure 1. Rapid product development projects are defined in this study as small scale product development activities which result in new sellable items in a company's product portfolio. Rapid product development projects are typically product development projects based on the company's existing product portfolio, but are still creating new products or services, and in that way do not fit the criteria of ECM projects. They are typically also smaller in scope than projects requiring heavy implementations of state-gate - type processes with multiple milestones.

\subsection{Characteristics of self-managing teams in product development}

In relation to the different processes of product development, there are several ways to organise product development activities. The cross-functional nature of product development makes it necessary for organisations to gather teams of experts to conduct development tasks to achieve speed and to have all required knowledge available for projects (Brettel et al., 2011). Examples of different types of product development teams include functional teams, lightweight project teams, heavyweight project teams, and self-managing (autonomous) teams (Wheelwright and Clark, 1992).

The benefits of self-managing teams come from productivity improvement, cost savings, performance effectiveness, and employee satisfaction (Cohen et al., 1996). Self-managing teams, also known as autonomous teams and self-organising teams, have been proposed to be most effective in development projects that include higher uncertainty and high degrees of innovation (Patanakul et al., 2012; Takeuchi and Nonaka, 1986). However, the rising interest of agile development methods in product development (e.g., Cooper, 2016; Karlstrom and Runeson, 2005; Rigby et al., 2016; Sommer et al., 2015) and the reliance on self-managing teams in agile methods (Chow and Cao, 2008; Highsmith, 2004) have increased the interest on self-management in all types of product development, as the focus of new product development (NPD) is going towards smaller projects (Cooper et al., 2004).

According to Wheelwright and Clark (1992), self-managing teams do not often follow existing organisational practices and procedures but create their own. This is also an integral view of many agile development methods where teams are able to influence their own best practices with retrospective thinking (Schwaber, 2004). Also, the fundamental strength of self-managing teams is the focus to smaller amount of tasks at hand (Wheelwright and Clark, 1992), which is also highlighted in agile methods through sprint thinking (Schwaber, 2004). The similarities of traditional self-managing product development teams and agile development's interest in self-organisation (Hoda et al., 2010; Moe et al., 2008) make it interesting to analyse how self-management is currently utilised in product development projects.

Takeuchi and Nonaka (1986) have described a 'self-organising project team' through the characteristics of autonomy, self-transcendence, and cross-functionality. ${ }^{1}$

In their description, autonomy means that management provides guidance, money and moral support for the team, but rarely intervenes in the teams' work on a day-to-day basis. Self-transcendence implies that the team tries to push themselves to 'the limit', starting with guidelines set by the management but elevating their goals along the development. Lastly, cross-functionality means that project team consists of members with varying functional specialities and characteristics. Co-location is also implied as one of the keys of the self-organising team by Takeuchi and Nonaka (1986), but this is 
included within the description of cross-functionality; "When all the team members are located in one large room, someone's information becomes yours, without even trying. ...You then start thinking in terms of what's best or second best for the group at large and not only about where you stand” (Takeuchi and Nonaka 1986).

Cohen et al. (1996) described self-managing teams as a group of interdependent individuals with the following characteristics: employees with interdependent tasks who are responsible for making a product, or providing a service; employee discretion over decisions such as work assignments, work methods, and scheduling of activities; teams have a variety of skills needed to perform the task (cross-functionality); team receives performance feedback.

Perhaps the most prominent description of a self-managing team comes from Wheelwright and Clark (1992). According to their description, the following characteristics define a self-managing team: team members are formally assigned; team members are dedicated to a single project; team members are co-located; project leader is given full control over the resources contributed by the different functional groups; project leader is the sole evaluator of the contribution made by individual team members; team is not required to follow organisational practices and procedures; team can establish own rewards and incentives; team is held accountable for project success.

Naturally, the descriptions of self-managing teams by Wheelwright and Clark (1992), Takeuchi and Nonaka (1986) and Cohen et al. (1996) overlap, but they are not exactly the same. When looking at self-management in the context of rapid product development, some of the characteristics presented above may not be valid, or applicable. In the case of incremental rapid product development projects, self-transcendence of a team is not as relevant as individual projects are not intended to be pushed further 'beyond limits' as Takeuchi and Nonaka described, but to create incremental improvements of existing products. Wheelwright and Clark (1992) have stated that the self-managing team can "excel at rapid, efficient new product and process development", partly in contrast to the view of Takeuchi and Nonaka (1986) about the self-managing team being most effective in larger projects where 'prior knowledge does not apply'. However, Wheelwright and Clark (1992) also acknowledge that 'autonomous' teams are often the birthplace for entirely new business because of their ability to think outside the scope of a single project.

Table 1 Characteristics of self-managing teams under analysis

\begin{tabular}{ll}
\hline \multicolumn{1}{c}{ Characteristics of a self-managing team } \\
\hline 1 & Team members are formally assigned \\
2 & Team members are dedicated to a single project \\
3 & Team members are co-located \\
4 & Project leader is given full control over the resources contributed by the different functional \\
& groups \\
5 & Project leader is the sole evaluator of the contribution made by individual team members \\
6 & Team is not required to follow organisational practices and procedures \\
7 & Team can establish own rewards and incentives \\
8 & Team is held accountable for project success \\
9 & Cross-functionality \\
\hline
\end{tabular}


Taking the description of Wheelwright and Clark (1992) as a starting point and by including the characteristic of cross-functionality as proposed by Takeuchi and Nonaka (1986) and Cohen et al. (1996), the following characteristics of a self-managing team were selected to be analysed in the case companies rapid product development models (Table 1).

\section{Research method}

To analyse how product development organisations currently utilise the characteristics of self-managing teams in rapid product development projects, a case study (Yin, 2009) was conducted with seven case companies. All case companies were interviewed and analysed regarding the different product development models they utilise and on their use of self-management in rapid product development. The data was collected through semi-structured interviews (Wengraf, 2001) with one or several respondents from each case company simultaneously present. A description of the case study protocol is presented in Figure 2.

Figure 2 Description of the case-study protocol used in this study

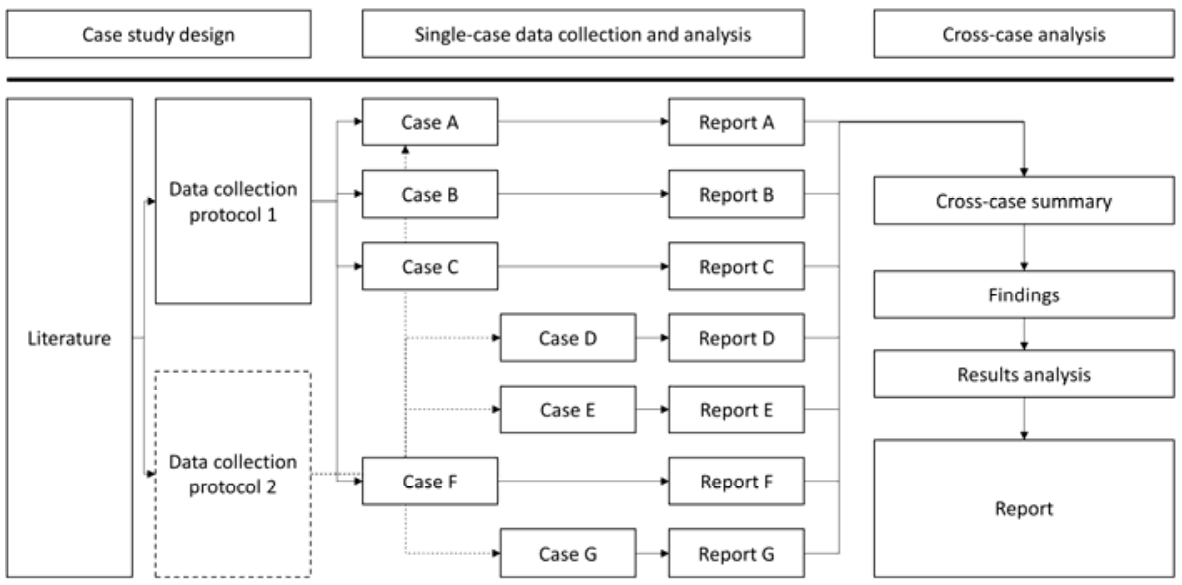

The analysed interview data was collected in two separate interview rounds. Both interview rounds were conducted during a research project in rapid product development and its application. The first interview round, conducted at companies A, B, C and F, was focused mainly on the use of self-managing teams in NPD and rapid product development. The second interview round, conducted at companies A, D, E and G, was a more comprehensive study of rapid product development, and in addition to self-management included other topics such as portfolio management, project management and process development.

Company A took part in both rounds, while the other companies took part in one of the interview rounds. The case companies were approached to involve as many interviewees as necessary to obtain all relevant information. The interviewees represented managerial roles, such as product managers, program managers and R\&D managers, and were selected based on their involvement in the organisations' rapid product development 
activities. The interviews were conducted either face-to-face or by phone, and were recorded and transcribed for later analysis. In some companies the interviews were conducted in several occasions due to the extent of the interview structure and time constraints. All questions in both interviews were open-ended to allow the respondents to discuss the issues that were most important to them openly.

The case organisations share a business-to-business sales model and come from varying fields of business to provide for a comprehensive sample of rapid product development. Five of the companies were large with only company $\mathrm{F}$ being mediumsized, and company G categorised as small. Company sizes, shown in Table 2, are based on the amount of persons employed by the company in accordance with EU's Eurostat classification (small 10-49, medium 50-249, large more than 250 persons employed). In all case companies, the length of large scale new product development activities was measured in years, but the length of rapid product development varied greatly, from a few days to nine months.

Table 2 Case company characteristics

\begin{tabular}{|c|c|c|c|c|}
\hline $\begin{array}{l}\text { Case } \\
\text { company }\end{array}$ & Field of business $^{\mathrm{a}}$ & $\begin{array}{l}\text { Company } \\
\text { size }^{\mathrm{b}}\end{array}$ & $\begin{array}{c}\text { Amount of } \\
\text { interviewees }\end{array}$ & $\begin{array}{c}\text { Interview } \\
\text { sessions }\end{array}$ \\
\hline A & $\begin{array}{l}\text { Wholesale of information and } \\
\text { communication equipment }\end{array}$ & Large & 6 & 3 \\
\hline B & $\begin{array}{c}\text { Manufacture of other electrical } \\
\text { equipment }\end{array}$ & Large & 2 & 1 \\
\hline $\mathrm{C}$ & $\begin{array}{l}\text { Manufacture of machinery for } \\
\text { mining, quarrying and construction }\end{array}$ & Large & 1 & 1 \\
\hline $\mathrm{D}$ & $\begin{array}{l}\text { Manufacture of electronic } \\
\text { components }\end{array}$ & Large & 4 & 2 \\
\hline $\mathrm{E}$ & $\begin{array}{l}\text { Manufacture of basic iron and steel } \\
\text { and of ferro-alloys }\end{array}$ & Large & 4 & 1 \\
\hline $\mathrm{F}$ & $\begin{array}{c}\text { Computer programming, } \\
\text { consultancy and related activities }\end{array}$ & Medium & 2 & 2 \\
\hline G & Security systems service activities & Small & 6 & 2 \\
\hline
\end{tabular}

Notes: a Classification according to EU NACE classification.

${ }^{\mathrm{b} C o m p a n y ~ s i z e ~ a c c o r d i n g ~ t o ~ E U ~ E u r o s t a t ~ c l a s s i f i c a t i o n . ~}$

The interview transcripts of the case companies were analysed considering their rapid product development projects. Some of the case companies had an existing internal classification between different projects (similar to Figure 1), and those companies which did not have the processes differentiated, were asked to consider rapid product development cases through examples.

\section{Case descriptions}

This section presents the results on the interviews in each case company. After the case descriptions, the results are combined and summarised in Table 3 . The results are analysed further in the following section. 


\subsection{Company $A$}

Company A is a worldwide telecommunication networks equipment provider. They have a wide range of product offerings varying from individual component and care services to large infrastructure networks with consulting and installation services. Company A had the highest amount of product development models in use among the case companies. The longest technology development projects at company A took up to five years and the shortest ECM tasks could be conducted in a month, so similar processes could not be utilised in all projects. In total, company A had described five different product development processes.

Company A did not have a development process that exactly fit the description for rapid product development. The difficulty at company A was that their 'fastest' product development model to create new sales items was too heavy and slow for small scale activities. The development lead-time for this 'product variant process' was estimated by the interviewees to be nine months, excluding the time required for business case analysis and decision-making.

Of the current product development models in company A, the ECM model that they utilise was the closest to rapid product development. The amount of ECM projects allowed for a dedicated line organisation for rapid product development. There were limits to the size of the project in terms of man months and cost, which cannot be exceeded for rapid product development. If those limits are exceeded, a more formal process in utilised. There was a lot of variation in the timeframe of rapid product development projects in company A, but a typical project lasted about two months.

From the viewpoint of company A, the success factors for rapid development involved having dedicated, co-located people working in the projects. In addition, the key to rapid development was face-to-face communication and a small team of key people. In relation to the small team, one of the difficulties related to rapid product development was finding competent resources for the projects. In addition to finding competent individuals, vague descriptions and requirements were also identified as an issue.

The nature of rapid development projects in company A did not require team members to be dedicated for single projects. The team members had significant influence on their own working practices and on the technical decisions during development, although goals were typically set at the beginning of the projects. During the engineering phase, there are no gates to disrupt the workflow of the engineers.

\subsection{Company $B$}

Company B produces specialised electronical equipment used in electric motors and energy production. They had defined their rapid product development model directly based on their product structure and utilised the same stage-gate model for all projects from longer new platform projects to rapid product development. A typical NPD project at company B would last two years, but rapid product development projects could be finished in six months.

All product development projects had to pass similar milestone and gate criteria, but there were changes in the level of verification during these gates for rapid product development. For longer NPD projects, such as new product platforms, development gates required a steering team approval with multiple stakeholders. Rapid product development project gates could be approved by the product manager in charge. Still, all 
projects were checked with similar criteria because company B felt this ensured quality throughout their product portfolio.

Rapid product development was used in certain pre-defined parts of the product structure which were available for customisation changes that could be done based on customer needs. The amount of rapid product development projects was significant in the company, with between 50 to a 100 projects conducted annually. Interestingly, company $\mathrm{B}$ differed from other analysed companies in allowing software changes to be done in rapid product development. Instead, they did not allow major hardware changes to be done to their product, as that would follow a heavy certification process.

In addition to following the same process description for rapid projects, all projects were conducted by the same product development organisation. The difference was that all rapid product development projects had one dedicated product and project manager to ensure project progress, and the inclusion of key account managers as the link to the customer. Engineers were nominated for the projects, but were not dedicated to individual projects. The engineers could also be located in different geographical sites around the world, so co-location of the team was not required in company B, also differing from other companies.

One difficulty identified was the availability of key competences. Company B stressed that prior knowledge of the product was key in the success of rapid product development projects. All teams were built as cross-functional teams, ensuring that the teams had always all resources needed to finish the project, but sometimes there were only certain individuals that could be selected for a certain modification.

Company B felt that rapid product development was a competitive advantage in their business area, and felt that its use was well understood in the company. Pre-defining what modifications can be done to the product in rapid product development was seen as the main strength and key to their scalable development process.

\subsection{Company $C$}

Company C manufactures heavy mining machinery which are sold worldwide. The company also provides service and care for the equipment they sell. Two distinct product development models could be identified in company C. A full-scale NPD process, which was utilised for regular, large sized product development projects, and an 'ad-hoc' rapid development process which was used for sales initiated product development projects. The rapid product development projects were typically modifications to existing products, which were required by a customer to finalise a sale. Rapid projects typically had only one gate to launch the project, and the engineering phase is done without gates to reduce lead-times. Rapid product development projects lasted for about 6 months in comparison to between one to three years for NPD projects.

In some cases, product management was involved in the decision-making to initiate the projects, but in worst cases the product development organisation heard about the projects once sales had already agreed with the customer to deliver the products. In terms of volume of product development, only about $10 \%$ of company C's projects were related to entirely new products, and the rest are some types of variations, or modifications of existing products. The ability to deliver rapid product development projects costeffectively was seen as a competitive advantage in company C. 
Company $\mathrm{C}$ tried to nominate the most senior engineers to rapid product development projects to enable self-organisation of work. Similar to other case companies, engineers' previous knowledge of the product was also seen as a key to deliver rapid product development projects. Face-to-face communication was preferred in all projects and this was no different in rapid product development. However, communication between sales and engineering was seen as an issue regarding the launch of rapid product development projects. After rapid product development projects had been approved, time was seen as a key indicator of project success.

Company $\mathrm{C}$ had a functional structure in their product development organisation, which they also utilised for rapid product development projects. Design and engineering were done 'ad-hoc' once the project was launched, meaning that the design teams were able to make technical decisions by themselves. The engineers were nominated to the rapid projects, but had other projects on-going at the same time. Their main responsibility was also to the functional head, not the project or product manager of the rapid product development project.

Company $\mathrm{C}$ utilised the same resources to conduct all of their product development projects. That meant that larger NPD projects were pushed back because the people working in them are forced to prioritise rapid product development tasks ahead of other projects. All of the product development staff of the company were collocated so there was no a need to collocate people specifically for rapid product development projects.

\subsection{Company $D$}

Company D manufactures electronic components and imaging equipment for specialised market segments. Three types of product development models could be identified to be in use by company D. A longer stage-gate development model was used for technology development and the creation of all new sales items that required changes in the delivery processes such as manufacturing or logistics. The second stage-gate model, which can be characterised as rapid product development, was used for creating new sales items modified from existing products. Third, the company used a separate ECM process to create new versions of existing products in production, which did not result in new sales items but improved versions of existing products.

The rapid product development model only utilised milestones in the beginning and ending of the development phase. During development, there were no milestones for the development team, and the projects' progress was followed in bi-weekly management meetings. Around 10 people of the 80 person development organisation were dedicated for the rapid product development projects. The rapid product development projects typically consisted of five to six people, whereas larger projects could use up to tens of people.

The selection criteria for rapid product development model in company D restricted the selection of any projects which modified certain product functions to omit longer verification phases. Similarly, if there was a need for new components or suppliers, the longer stage-gate model would be used because of the included supplier validation phase.

Annually, company D conducted around 20 rapid product development projects, which resulted in approximately 150 new sales items for the company's product portfolio. Interestingly, the scope and timeframe of ECM-projects could sometimes be larger than the rapid product development projects. 
For the success factors considering rapid product development, company D named a defined product platform, effective product data management, dedicated development resources, clear selection criteria for the different development models, and the co-location of the dedicated resources. Communication during development projects was also defined as one key to successful rapid product development projects. Company D had allocated all of their dedicated resources to one site to ensure effective face-to-face communication within the rapid product development projects.

Developers were nominated for all development projects using a resource allocation matrix, and similarly to other analysed companies, could work with multiple projects at the same time. The teams had the authority to define some of their working methods during rapid product development projects, but had to follow some guidelines defined by the organisation. These guidelines included, for example, the cost and timeframe of the project, what components could be modified, and the use of existing component suppliers.

\subsection{Company E}

Company E manufactures iron, steel and metal alloys. They offer both raw materials and processed steel products such as construction solutions. Two product development models were in use at company E. An NPD process for creating entirely new product lines lasting years, and a rapid development workflow for creating minor modifications to existing products. The average time to create a new product variant with rapid product development was estimated to only be around two days. As the production lead-times of company E were measured in weeks, the delay of creating a rapid product variant was not seen to cause noticeable delays to product delivery. The rapid product development organisation used a workflow to ensure that all necessary steps were done during the rapid product development tasks.

Rapid product development had its own line organisation, and the organisation was utilised to create, or answer all sales related product requests. The organisation relied on the technical competence of the engineers for all the steps to be completed during the tasks. The line organisation was very self-organised and adaptive to modify its routines. In addition to sales requests, the same line organisation was also utilised for ECM. Even though the line organisation consisted of around 20 people, they handled over 5,000 development requests annually. Over half of the requests were fulfilled with the company's existing product portfolio without any development effort, but sales or other sources of the requests lacked knowledge or visibility to know about this beforehand. By limiting the possibility of changes to the product in rapid product development, company $\mathrm{E}$ had been able to create a very customer-focused approach in their sales. The sales-induced rapid product development capabilities were seen to support the company strategy.

Issues with rapid product development were very similar to the other analysed companies. Unclear requirements from sales caused big issues, especially with the large amount of arriving requests. The interviewees also stated that knowledge transfer was one issue within the organisation, and that many requests could have been solved by sales themselves if they had all the knowledge of the products better available to them.

The entire line organisation was co-located, and the engineers worked full-time with rapid product development tasks. All engineers had cross-functional knowledge of the 
product portfolio, material science, production, IT systems, and sales. Although the tasks were given to individual engineers, they worked as a co-located team which was able to consult each other if necessary. Face-to-face discussions were preferred, although the interviewees stated that emails were also used as one form of communication.

\subsection{Company F}

Company $\mathrm{F}$ is a development consultancy organisation that specialises in product design, production design and product concepting. Company $\mathrm{F}$ had only identified one development process to be used in their projects, but it was used more as a guideline instead of a strict process that needed to be followed. Company F was different from the other analysed companies in that its core business was project-based. The company was only a few years old, and the interviewees acknowledged that their product development processes were yet to be fully described.

Rapid product development projects at company $\mathrm{F}$ were identified to be small-scale conceptualisation projects, which were limited in the scope of design work. These rapid projects would usually be conducted with a team of around five people, whereas the larger design projects could include up to 30 people. The process of rapid product development projects was described by the interviewees as ad-hoc, and the organisations relied on the teams' competence to successfully finish projects.

All project teams were self-organising their daily tasks. The progress of projects was followed in weekly meetings, but the progress was ensured by constant face-to-face communication. Projects had a nominated project manager, but the technical design decisions could be done by the team members.

The entire organisation worked from a single site, which was seen by the company as a huge competitive advantage, and one key to their efficiency. In addition to the colocation of the entire development organisation, the collective knowledge and expertise of the development personnel was seen as a big factor in the company's ability to make successful projects.

Although the team members would not sit directly next to each other, they were still in the same space which was seen in company $\mathrm{F}$ to be adequate to support effortless communication between team members. Actually, as all designers were communicating face-to-face, one interviewee noted that they sometimes have issues with documentation of the projects as the decisions are made on the fly by the team. The teams were also highly cross-functional, and there were mainly cross-functional designers in the company to support the nature of their design work.

Similarly to other companies, the designers in rapid projects were not dedicated to single projects. A difference between company $\mathrm{F}$ and other analysed companies was that they limited the amount of projects for single designers to three, so that there would not be too much task switching interrupting the designers work.

\subsection{Company G}

Company G manufactures electronic locking mechanisms and offers both physical products and related care and support services. Three product development models could be identified at company G. A typical NPD project lasted from one to one and a half year, and a typical rapid development projects were finished between one to six months. Much of the lead-time during rapid product development was caused by ordering prototypes or 
parts from suppliers. The actual development effort in rapid projects was evaluated by the interviewees to be 'in weeks, not months' and even days in the fastest tasks.

In company $\mathrm{G}$, rapid product development was used to create customer - or location specific variations to their product to increase sales revenue. The rapid product development process at company $G$ was a modified version of their full-scale NPD process. Rapid product development projects had to fulfil certain gate-criteria during the process, but the gate approvals could be done by a product manager or the designers themselves. Technical decisions could also be done by the development team or individuals and the company relied on their developers' competence to conduct the technical decisions.

The company limited the use of rapid product development model to low-risk and low investment projects, which led to reduced requirements for project planning and feasibility studies to allow for more flexibility. In addition to limiting changes to product functionality, all projects that required new suppliers utilised a full-scale NPD process. Rapid product development cases were typically handled by two two-person teams, who were competent enough to design the changes to the product by themselves.

The success criteria for effective rapid product development was to have clear requirements for the designers, so that they could do the project directly without getting any more information from other functions or the customer. In addition to clear requirements, having an informal process with light bureaucracy was also integral to achieving fast deliveries. All development staff of the company was seated in one location, which helped communication of issues in case any were noticed. In contrast to other analysed companies, company $\mathrm{G}$ did not see cross-functionality as relevant for their rapid product development. As they had limited their rapid projects to include only certain machinable parts, the designers only needed specific expertise to finish the projects.

The company also did not track the duration of the projects, and identified that as an issue with rapid product development. The projects were often taken in by large numbers because they were considered small and low-risk, but had constrained the limited resources who were responsible for these projects as management did not have knowledge of all on-going activities. Large numbers of on-going projects with only a few designers meant that dedicating the designers for individual projects was not possible.

\subsection{Summary}

Table 3 presents the information of the analysed companies to summarise and clarify the provided information. The table presents the typical length of NPD and rapid product development projects, the amount and types of product development models in use, criteria for when rapid product development model is used and nominated success factors for rapid product development. 
Table 3 Characteristics of rapid product development and product development models in the analysed companies

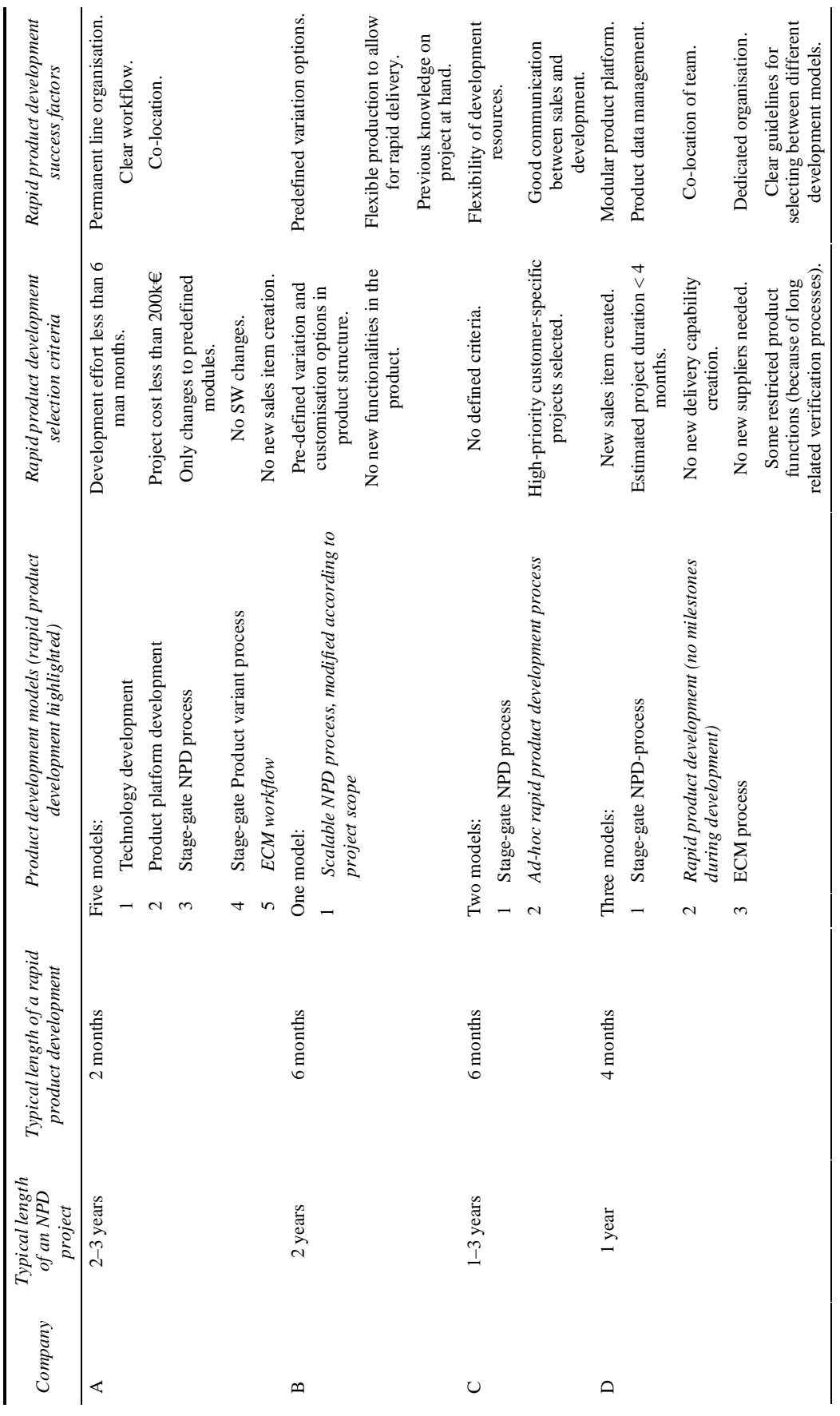


Table 3 Characteristics of rapid product development and product development models in the analysed companies (continued)

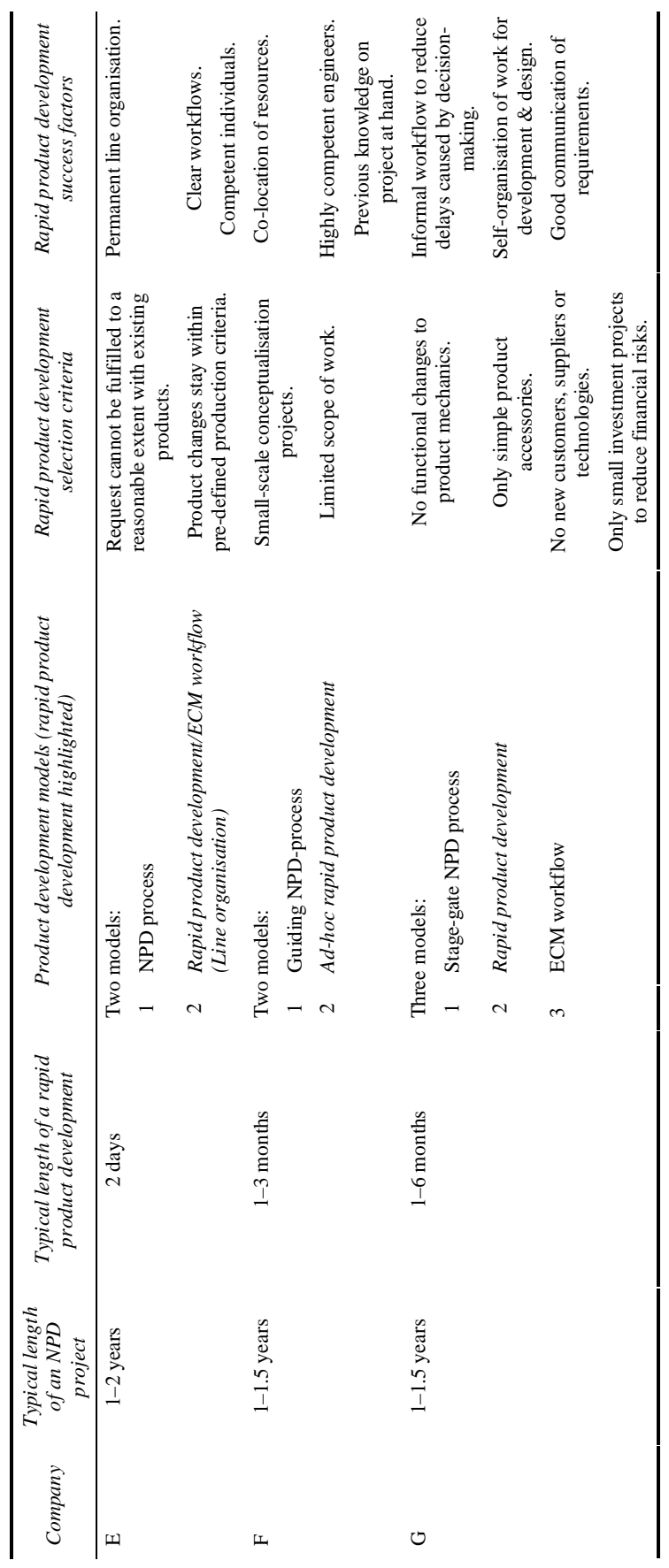




\section{Results analysis}

The following section analyses the results of the interviews in the case companies presented in the previous section. The first subsection will present the results in relation to RQ1, and the second subsection will discuss the findings for RQ2.

\subsection{Characteristics of self-managing teams in rapid product development projects}

The usage of the characteristics of self-managing teams varied in the case companies. The usage of the individual characteristics are presented in Table 4.

Table 4 Characteristics of self-managing teams identified in the case companies' rapid product development models

\begin{tabular}{|c|c|c|c|c|c|c|c|c|}
\hline \multirow{2}{*}{\multicolumn{2}{|c|}{ Characteristic }} & \multicolumn{7}{|c|}{ Company } \\
\hline & & \multirow{2}{*}{$\frac{A}{\mathrm{X}}$} & \multirow{2}{*}{$\frac{B}{x}$} & \multirow{2}{*}{$\frac{C}{\mathrm{x}}$} & \multirow{2}{*}{$\frac{D}{\mathrm{x}}$} & \multirow{2}{*}{$\frac{E}{\mathrm{X}}$} & \multirow{2}{*}{$\frac{F}{\mathrm{x}}$} & \multirow{2}{*}{$\frac{G}{\mathrm{x}}$} \\
\hline 1 & $\begin{array}{l}\text { Team members are } \\
\text { formally assigned }\end{array}$ & & & & & & & \\
\hline 2 & $\begin{array}{l}\text { Team members are } \\
\text { dedicated to a single } \\
\text { project }\end{array}$ & - & - & - & - & - & - & - \\
\hline 3 & $\begin{array}{l}\text { Team members are } \\
\text { co-located }\end{array}$ & $\mathrm{x}$ & - & $\mathrm{X}$ & $\mathrm{x}$ & $\mathrm{X}$ & $\mathrm{X}$ & $\mathrm{x}$ \\
\hline 4 & $\begin{array}{l}\text { Project leader is given full } \\
\text { control over the resources } \\
\text { contributed by the } \\
\text { different functional groups }\end{array}$ & - & - & - & - & $\mathrm{X}$ & - & - \\
\hline 5 & $\begin{array}{l}\text { Project leader is the sole } \\
\text { evaluator of the } \\
\text { contribution made by } \\
\text { individual team members }\end{array}$ & - & - & - & - & - & - & - \\
\hline 6 & $\begin{array}{l}\text { Team is not required to } \\
\text { follow organisational } \\
\text { practices and procedures }\end{array}$ & $\mathrm{O}$ & - & $\mathrm{O}$ & $\mathrm{O}$ & - & $\mathrm{O}$ & $\mathrm{O}$ \\
\hline 7 & $\begin{array}{l}\text { Team can establish own } \\
\text { rewards and incentives }\end{array}$ & - & - & - & - & - & - & - \\
\hline 8 & $\begin{array}{l}\text { Team is held accountable } \\
\text { for project success }\end{array}$ & - & - & - & - & - & - & - \\
\hline 9 & Cross-functionality & $\mathrm{x}$ & $\mathrm{x}$ & $\mathrm{x}$ & $\mathrm{x}$ & $\mathrm{x}$ & $\mathrm{x}$ & - \\
\hline
\end{tabular}

Notes: $\mathrm{x}=$ applies to the organisation; $-=$ does not apply to the organisation;

$\mathrm{O}=$ somewhat applies

Based on the results it appears that the analysed companies utilise similar characteristics of self-managing teams in rapid product development projects. Nevertheless, the only characteristic utilised in all the companies was the formal nomination of team members to rapid product development projects. A key to the success of rapid product development projects was found to be having highly competent people as part of the rapid product development projects. As the nature of rapid product development projects is often incremental, having knowledge on the product being modified is a key to fast and 
successful rapid product development projects. There is no time to study the product or technology in use when the delivery needs to be fast. The nature of work is demonstrated by a comment by a product line manager of company $C$ who stated: "If it is a new guy who does not know anything what has been done earlier, he is not a rapid project person".

Excluding company B, all the companies also identified co-location of the team to be highly important in rapid product development and regard co-location as a key to effective communication. Co-locating the team members also reduced the need of formal documentation and communication such as e-mails when the entire team is on the same page during the development. In relation to previous characterisations of self-managing teams, co-location seems to be of high relevance in rapid product development, although e.g., Cohen et al. (1996) and Takeuchi and Nonaka (1986) do not explicitly mention it as being necessary.

With the exception of company G, all companies also felt that cross-functionality of the development team is a key aspect in rapid product development. As the nature of the projects necessitates effective decision-making, it is rarely possible for the development team to look for help or answers outside of the team. Even company G mentioned the importance of having knowledgeable engineers in rapid product development tasks, but the nature of their rapid tasks did not require cross-functionality from the engineers working on the tasks.

One of the most interesting results was in the requirements to follow organisational procedures. A commonality in all analysed companies was the ability of the rapid product development teams to influence and decide on their daily working practices, and that apart from company $\mathrm{B}$, the teams were able to deviate from the typical development processes that the companies employed. This was illustrated by the comment of company A's program manager: "For me, rapid development and process, they are not in the same sentence".

However, being able to deviate from the process did not give the team's full authority to disregard all process descriptions. In five of the seven companies, formal kick-off and project approval meetings were held, and there was a definition for project completion, even though there may not have been a clear process description on what happens during the project. As the rapid product development projects have to fit within the companies' existing product portfolios, there were clear guidelines on what the teams have to complete in order for the project to be delivered. This is in contrast to Wheelwright's and Clark's (1992) description of self-management, where teams can dictate their own work processes entirely.

The characteristics that are in use in the analysed companies (formal assignment of team members, co-location, cross-functionality and self-organisation of work), show similarities with agile methods as proposed by Hoda et al. (2010) and Moe et al. (2008). This finding supports the rise of agile methods in product development (Rigby et al., 2016; Sommer et al., 2015). Some of the companies identified the impact of agile methods within their rapid product development projects, as they have had good feedback from these methods in their software development organisations.

Many of the analysed characteristics of self-managing teams were not utilised by the case companies in their rapid product development projects. Perhaps the most obvious difference to the characteristics of self-managing teams was that the companies did not dedicate people to single projects when it comes to rapid product development. This difference is perhaps easy to understand considering that these characteristics have been 
described for teams that work on larger projects. In smaller projects, it is not as useful to dedicate people to single projects. Cooper (2013) has shown that there is a correlation between product development performance and teams focusing on single projects, but the results of this study show that analysed companies prefer to allow people to work between multiple projects while working with rapid product development.

Similarly, there was a difference between the case companies' experiences and literature in the evaluation and rewarding of rapid product development teams. With incremental projects that are intended to complement the existing product portfolio of a company, there were typically clear goals for the project completion. Rapid product development projects were typically done to make a sale or fulfil a specific customer request. Therefore, the criteria of project success were generally defined already at the beginning of the project. As the team members were not dedicated to a single project, there was generally no need to evaluate their performance based on single projects. Rewarding of rapid product development team members was also typically non-existent in the smaller projects, although earlier research has showed that from an individual's perspective, rewarding may be a key issue in self-managing teams (Levi and Slem, 1995).

All case companies considered that other organisational incentives and rewarding were adequate and that there was no need to incentivise team members based on smaller projects. While not giving the teams additional incentives, the team members were also not fully accountable for project successes either. Most companies saw rapid product development projects as tactical activities that supported sales. This meant that there was typically a direct request or a sale already made which started the rapid product development project. This reduced the financial risk of the project as the completion of the project would already materialise as a sale.

As the team members were not dedicated to single projects, most of the companies did not give their project leaders the full control of their resources either. However, in some organisations such as company $\mathrm{E}$, the allocation of resources differed from the others in the sense that rapid product development projects has a dedicated organisation. As there were dedicated resources that only worked in rapid product development projects, it enabled the line manager to control the resources as he saw the best.

Based on the results, it appears that some of the characteristics of self-managing teams do not apply to rapid product development projects, but some apply very well and are utilised to a high extent. The smaller scope and incremental nature of rapid product development projects makes some of the characteristics irrelevant, but there are also clear benefits to some of the characteristics. The results show that companies utilise self-organisation of work in rapid product development projects, but do not delegate all levels of management to the team. Rewarding, evaluation, resource allocation and accountability are still left for other levels of management and not the team itself. With the inclusion of co-location, the characteristics of self-managing teams that were in use in the analysed companies' rapid product development are perhaps closest to the description by Cohen et al. (1996).

\subsection{Case companies' success factors for rapid development}

The success factors for rapid product development perceived by the analysed companies can be seen in Table 3. The success factors for rapid development varied in the case companies, but there were clear similarities between the companies and to the characteristics of self-managing teams. A permanent line organisation was utilised for 
rapid product development in three of the seven organisations (A, D and E) to ensure that the people working on rapid projects knew how to handle the specific nature of the projects. Additionally, two other organisations (B and F) recognised that it is vital to have previous knowledge on the product at hand to successfully deliver the rapid projects.

Co-location of the development resources and efficient communication was mentioned explicitly as a success factor by six of the companies, with only company $\mathrm{B}$ letting rapid product development projects to be done by a multisite setup. Co-location of team members and effective face-to-face communication was one of the most striking similarities between the success factors of rapid product development and the characteristics of self-managing teams.

One major commonality among the success factors was to have a clear, but flexible workflow to ensure that the rapid projects would be conducted in a repeatable fashion, but without excessive delays. With the exception of company $F$, the other six case companies utilised a stage-gate type NPD process in larger projects. Five of those six companies had a more relaxed approach to rapid projects in terms on decision-making to accommodate for a flexibility during development, and many described this flexibility as a success factor as well. However, flexibility did not mean allowing teams to conducted rapid product development projects as they pleased. A clear workflow for the projects makes sure that all necessary steps are done during development, although the steps may not require a definitive approval from somebody outside the team. The case companies relied on the engineers' competence during rapid product development to ensure quality is preserved and the project finished successfully. As mentioned earlier, this is contradictory to the characteristic of Wheelwright and Clark (1992) of allowing full authority to the teams to design their own practices. Instead, the case companies had set guidelines to be followed, but allowed the teams some flexibility to fulfil those guidelines, especially on the technical side of the projects.

Based on the results presented above, the best practices for using self-management in rapid development teams comes from assigning team members formally to specific projects, co-locating the team, making the team cross-functional and allowing the team some flexibility in decision-making during project delivery. The team must still not operate without any guidelines, and a rapid product development workflow guiding the work should be in place to ensure progress. The workflow can be based on an existing NPD process, but should have reduced managerial interruptions and allow self-management within a highly competent team especially in technical decisions. Co-locating the development team and supporting efficient, face-to-face communication is also a key contributing factor for rapid product development. It may be useful for development teams or team members to be dedicated for rapid product development, but they should not be dedicated to individual projects.

There may be some barriers for self-management in rapid product development as well. Having highly competent team members is seen as a key for rapid product development and if there are no available team members with previous knowledge of a product being developed, the use of a rapid product development model should be reconsidered at the start of the project.

An organisation should have a well-defined NPD process to be used as a basis for a rapid product development workflow. Without a clear workflow, the rapid projects will intuitively be prioritised ahead of the NPD projects, which can cause disruptions throughout the product development portfolio. There should also be a clearly defined 
rules in place as to what projects can be conducted with a rapid product development workflow. Without these rules in place, it is easy for rapid product development workflow to become 'the norm' for product development projects, as it may be seen as a faster way to conduct projects. However, rapid product development should not be seen as the main mode of product development, but as a complementary model to support the product development resources by taking smaller tasks out of the NPD project portfolio. The rules for selecting between product development models may include (but are not limited to) project scope, development lead time, product structure and project cost.

\section{Conclusions}

This study analysed the use of characteristics of self-management in rapid product development teams and the success factors of rapid product development as perceived by the case companies. Based on interviews conducted in seven companies, formal assignment of team members, co-location of the development teams, and crossfunctionality were found as the most utilised characteristics of self-managing teams at the companies' rapid product development models. Additionally, nearly all analysed organisations noted that they allow rapid product development teams to organise their own working practices and procedures, but also had guidelines on what is required for project delivery, controlled by meetings or practices and the beginning and end of the projects.

Many of the characteristics of self-managing teams were not utilised widely in rapid product development by the analysed companies. Team members were typically not dedicated to single projects, project leader did not have full control of the resources working within a project, project leader did not solely evaluate the success of individuals, the team was not able to set their own incentives or rewards, and the team members were not fully accountable for project success. The scope and nature of rapid product development projects, however, provide some explanation to why many of the characteristics were not identified to be in use.

Common perceived success factors for self-managing teams in rapid product development were dedicating competent developers for rapid projects, co-locating the development team, effective face-to-face communication and implementing a defined, but flexible workflow for rapid product development. Identified barriers for utilising self-managing teams in rapid product development were lack of highly competent developers with enough knowledge on the products, lack of a well-defined NPD process as a basis for rapid product development workflow and lack of rules for selecting between the product development models.

For industry managers, the results of this study imply that selected characteristics of self-managing teams can be utilised to achieve improvements in rapid, incremental development projects. The results also show that implementing several product development models in parallel can be beneficial for a product development organisation, as long as the models and the rules on how they are applied are made clear in advance. Rapid product development projects should not only be pushed through and prioritised over long-term product development projects, but they should be conducted with similar focus in terms of planning, resource utilisation and management. This way smaller tasks can be finished more effectively and longer projects are not put on hold while waiting for resources, which supports a company's profitability in both short and long term. 
From a scientific viewpoint, this study adds to the existing scientific discussion by providing empirical data on rapid product development models, and smaller projects, when the focus of product development literature is often in larger NPD projects. The results of this study suggest many similarities between agile development methods and rapid product development, and these similarities could provide additional information on what characteristics of agile methods support smaller product development projects. In addition to the self-managing team, many facets of agile development methods could be identified to be in use in rapid product development projects. Hence, further research could be conducted by focusing on the use of agile methods in rapid product development projects. Further research could also be conducted to validate the results of this paper in larger sample sizes. Research could be done with a more comprehensive and specified interview study, or a comprehensive survey study which would allow for quantitative analysis between different sized companies and business areas, for example.

Generalisation of the results of this paper should be done while noting the diversity of the case companies. The various business areas and sizes of the case companies provide for a comprehensive look into the phenomena of rapid product development, but the diverse environments may affect the comparability of the findings. The separation of product development models used in this study is subject to discussion. In smaller organisations, all four development models may not be applicable. However, based on previous analysis with the companies, it has been found that typically there are several models for product development, even though they may not always be described with official documentation.

Although self-managing teams have previously described as being useful in larger, innovative product development projects, it is clear that there is interest and use for many of its characteristics in smaller projects as well. The rising interest in agile methods also shows that there is still a lot of interest to find more effective ways to organise product development.

\section{References}

Barczak, G., Griffin, A. and Kahn, K.B. (2009) 'Perspective: trends and drivers of success in NPD practices: results of the 2003 PDMA best practices study', Journal of Product Innovation Management, Vol. 26, N. 1, pp.3-23.

Bernard, A. and Fischer, A. (2002) 'New trends in rapid product development', CIRP Annals - Manufacturing Technology, Vol. 51, No. 2, pp.635-652.

Brettel, M., Heinemann, F., Engelen, A. and Neubauer, S. (2011) 'Cross-functional integration of R\&D, marketing, and manufacturing in radical and incremental product innovations and its effects on project effectiveness and efficiency', Journal of Product Innovation Management, Vol. 28, No. 2, pp.251-269.

Bullinger, H.J., Warschat, J. and Fischer, D. (2000) 'Rapid product development - an overview', Computers in Industry, Vol. 42, Nos. 2/3, pp.99-108.

Chow, T. and Cao, D. (2008) 'A survey study of critical success factors in Agile software projects', Journal of Systems and Software, Vol. 81, No. 6, pp.961-971.

Clark, K.B. and Fujimoto, T. (1991) Product Development Performance, Harvard Business School Press, Boston.

Cohen, S.G., Ledford, G.E. and Spreitzer, G.M. (1996) 'A predictive model of self-managing work team effectiveness’, Human Relations, Vol. 49, No. 5, pp.643-676. 
Cooper, R.G. (1993) Winning at New Products: Accelerating the Process from Idea to Launch, 2nd ed., Addison-Wesley, Boston.

Cooper, R.G. (2013) 'New products: what separates the winners from the losers and what drives success', The PDMA Handbook of New Product Development, 3rd ed., John Wiley \& Sons, Hoboken.

Cooper, R.G. (2014) 'What's next? After stage-gate', Research-Technology Management, Vol. 57, No. 1, pp.20-31.

Cooper, R.G. (2016) 'Agile-stage-gate hybrids', Research-Technology Management, Vol. 59, No. 1, pp.21-29.

Cooper, R.G., Edgett, S.J. and Kleinschmidt, E.J. (2004) 'Benchmarking best NPD practices-II', Research-Technology Management, Vol. 47, No. 3, pp.50-59.

Devar, R.D. and Dutton, J.E. (1986) 'The adoption of radical and incremental innovations: an empirical analysis’, Management Science, Vol. 32, No. 11, pp.1422-1433.

Garcia, R. and Calantone, R. (2002) 'A critical look at technological innovation typology and innovativeness terminology: a literature review', The Journal of Product Innovation Management, Vol. 19, No. 2, pp.110-132.

Gautam, N. and Singh, N. (2008) 'Lean product development: maximising the customer perceived value through design change (redesign)', International Journal of Production Economics, Vol. 114, No. 1, pp.313-332.

Highsmith, J. (2004) Agile Project Management: Creating Innovative Products, Addison-Wesley, Boston.

Hilletofth, P., Ericsson, D. and Lumsden, K. (2010) 'Coordinating new product development and supply chain management', International Journal of Value Chain Management, Vol. 4, Nos. 1/2, pp.170-192.

Hoda, R. and Noble, J.M.S. (2010) 'Organizing self-organizing teams', Proceedings of the 32nd ACM/IEEE International Conference on Software Engineering, Vol. 1, pp.285-294.

Jarratt, T.A.W., Eckert, C.M., Caldwell, N.H.M. and Clarkson, P.J. (2011) 'Engineering change: an overview and perspective on the literature', Research in Engineering Design, Vol. 22, No. 2, pp.103-124.

Kaikkonen, H., Hänninen, K. and Haapasalo, H. (2016) 'Organizing product development for rapid response. A case study on approaches towards unexpected product development needs', Proceedings of the 22nd ICE/IEEE International Technology Management Conference, IEEE Computer Society.

Karlstrom, D. and Runeson, P. (2005) 'Combining Agile methods with stage-gate project management', IEEE Software, Vol. 22, No. 3, pp.43-49.

Langerak, F. and Hultink, E.J. (2008) 'The effect of new product development acceleration approaches on development speed: a case study', Journal of Engineering and Technology Management, Vol. 25, No. 3, pp.157-167.

Langfred, C.W. (2007) 'The downside of self-management: a longitudinal study of the effects of conflict on trust, autonomy, and task interdependence in self-managing teams', Academy of Management Journal, Vol. 50., No. 4, pp.885-900.

Levi, D. and Slem, C. (1995) 'Team work in research and development organizations: the characteristics of successful teams', International Journal of Industrial Economics, Vol. 16, No. 1, pp.29-42.

Millson, M.R., Raj, S.P. and Wilemon, D. (1992) 'A survey of major approaches for accelerating new product development', Journal of Production Innovation Management, Vol. 9, No. 1, pp.53-69.

Moe, N.B., Dingsøyr, T. and Dybå, T. (2008) 'Understanding self-organizing teams in Agile software development', Proceedings of the 19th Australian Conference on Software Engineering, IEEE Computer Society, pp.76-85.

Patanakul, P., Chen, J. and Lynn, G.S. (2012) 'Autonomous teams and new product development', Journal of Product Innovation Management, Vol. 29, No. 5, pp.734-750. 
Rigby, D.K., Sutherland, J. and Takeuchi, H. (2016) 'Embracing agile’, Harvard Business Review, Vol. 94, No. 5, pp.40-50.

Schwaber, K. (2004) Agile Project Management with Scrum, Microsoft Press, Washington.

Smith, P.G. and Reinertsen, D.G. (1997) Developing Products in Half the Time: New Rules, New Tools, John Wiley \& Sons, Hoboken.

Sommer, A.F., Hedegaard, C., Dukovska-Popovska, I. and Steger-Jensen, K. (2015) 'Improved product development performance through agile/stage-gate hybrids. The next-generation stage-gate process?’, Research-Technology Management, Vol. 58, No. 1, pp.34-44.

Takeuchi, H. and Nonaka, I. (1986) 'The new product development game', Harvard Business Review, Vol. 64, No. 1, pp.137-146.

Wengraf, T. (2001) Qualitative Research Interviewing, Sage publications, London.

Wheelwright, S.C. and Clark, K.B. (1992) Revolutionizing Product Development: Quantum Leaps in Speed, Efficiency, and Quality, The Free Press, New York.

Wright, I.C. (1997) 'A review of research into engineering change management: implications for product design', Design Studies, Vol. 18, No. 1, pp.33-42.

Yin, R.K. (2009) Case Study Research: Design and Methods, 4th ed., Sage publications, Thousand Oaks.

Zhou, Y. and Zhao, W. (2010) 'A study on new product development using a decision circumstance model’, International Journal of Value Chain Management, Vol. 4, No. 4, pp.380-399.

\section{Notes}

1 Takeuchi and Nonaka (1986) use the term ‘cross-fertilisation'. 